\title{
Treatment of dental anomalies self-ligating system damon
}

\begin{abstract}
Currently, there are two main types of self-ligating Bracket systems: active and passive. Active is when the wire is pressed into the slot of the bracket, passive - is when the wire is more free into the slot. In Damon's passive self-ligating system super elasticity of the wire can be more obvious because of the low friction between the wire and the slot of the braces, so the wire develops very weak forces in the process of treatment. In passive self-ligating systems we do not require such additional devices, such as headgear, rapid palatal expansion, etc. This is significantly saves the doctor's work time as well the patient time. Individual torque values of the braces reduce the extraction option in the crowding cases, which improves of face aesthetics: we can avoid flattening of the face appearance and buccal black corridors, etc.
\end{abstract}

Volume 9 Issue 2 - 2018

\author{
Aiman Obeid \\ Department of Orthodontics, Belarusian State Medical \\ University, Belarus
}

Correspondence: Aiman Obeid, Department of Orthodontics, Belarusian State Medical University, Belarus, Email aimanobeid@gmail.com

Received: January 18, 2017 | Published: March 07, 2018

\section{Objective}

To analyze the changes occurring at the level of the teeth, arches and occlusion during treatment of dentoalveolar anomalies with Damon braces without removing individual teeth.

\section{Material and methods}

34 pairs of jaws models of adult patients were measured with various anomalies before and after treatment with Damon braces according to the following parameters: length, width of dental arch in the region of premolars, molars and canines, the length of the anterior segment of the arch. The results obtained were been compared before and after treatment, with the calculated rate for Linder-Hart and Korkhaus.

\section{Results}

The length of the dental arch of the upper and lower jaws after carried out treatment has not increased significantly. The received data are confirmed by a number of researchers. ${ }^{1-4}$ The greatest expansion of dental arcs occurred in the region of the first premolars of the upper and lower jaws (by $3.70 \pm 0.79 \mathrm{~mm}$ and $3.85 \pm 0.81$ $\mathrm{mm}$ respectively). However, in comparison with the Linder-Hartou norm of the upper jaw, the width of the dental arch remained less than the norm by $1.77 \pm 0.67 \mathrm{~mm}$, and at the bottom it became more than normal at $2.07 \pm 0.79 \mathrm{~mm}$. This discrepancy, apparently, indicates the identity of the width of the upper and lower dental arches, which is reported in the studies of several authors. In the field of molars the expansion of the upper dental arch is $1.54 \pm 0.77$, on the lower jaw expansion is not reliable. In comparison with the Linder-Hartu normthe width of the upper dental arch in the molar region did not reach the individual norm by $2.95 \pm 0.66 \mathrm{~mm}$. In the region of canines, both on the upper and lower jaws reliably significant changes did not occur. The length of the anterior segments of the upper and lower dental arches is practically has not changed after treatment. In comparison with the norm calculated by Korkhaus their length before treatment was less by $2.36 \pm 0.6 \mathrm{~mm}$ and $2.28 \pm 0.6 \mathrm{~mm}$, respectively. After treatment, the length of the anterior section of the upper dental arch did not reach norms by $1,28 \pm 0,48 \mathrm{~mm}$, and the lower $1,70 \pm$
$0,48 \mathrm{~mm}$. This does not contradict conclusion based on own research and confirmed works of other authors, about lack of significant changes in the length of dental arches, including number of their anterior segments, before and after treatment with Damon brackets.

\section{Conclusion}

Major changes occur due to a significant expansion of dental arches in the premolars and molars areas. There are no significant changes in the inter-canine distance and the anterior segment length as well. The received data do not confirm the assumptions of some authors about the occurrence of a gum recession, protrusions of incisors and canines after treatment with Damon brackets. Studying models of the jaws of patients before and after treatment with Damon system, as well as comparing the results with the existing norms showed high efficiency of the method, due to precise information of the brackets, wires, elastic elements proposed by the author and programmed for best result.

\section{Acknowledgment}

None.

\section{Conflict of interest}

None.

\section{References}

1. Adkins MD, Nanda RS, Gurrier GF. Arch perimeter changes on rapid palatal expansion. Am J Orthod Dentofacial Orthop. 1990: 97(3):194-199.

2. Akkaya S, Lorenson S, Usem TT. Turkey European Journal of Orthodontis. 1998;20:255-261.

3. Germane N, Lindauer SJ, Rubenstein LK, et al. Increase in arch perimeter due to orthodontic expansion. Am J Orthod Dentofacial Orthop. 1991;100(5):427-100.

4. Norosi H, Diavidi GE, Moeinzad H, et al. Prediction of arch perimeterchanges due to orthodontic treatment. Am JOrthod Dentofacial Orthop. 2002;122(6):607-122. 